\title{
PENGEMBANGAN PETA POTENSI DESA BERBASIS SPASIAL UNTUK MENDUKUNG PERENCANAAN PEMBANGUNAN DESA DI KECAMATAN BUNGA RAYA KABUPATEN SIAK
}

\author{
Suwondo*), Almasdi Syahza, Musrifin Galib, dan Reby Oktarianda \\ Pusat Pengembangan Infrastruktur Informasi Geospasial, Universitas Riau \\ ${ }^{*}$ Email: wondo_su@yahoo.co.id
}

\begin{abstract}
ABSTRAK
Perencanaan pembangunan desa membutuhkan informasi dalam bentuk data spasial yang tepat dan akurat, sehingga dapat dimanfaatkan untuk menganalisis kebutuhan pembangunan pada aspek lingkungan, ekonomi, dan sosial. Pada faktanya menunjukkan terbatasnya informasi spasial terkait administrasi desa, potensi desa dan toponimi. Pengembangan peta potensi desa berbasis spasial bertujuan untuk menyajikan informasi spasial sehingga dapat digunakan dalam perencanaan pembangunan desa. Peta spasial dikembangkan melalui pendekatan partisipatif dengan melibatkan mahasiswa Universitas Riau. Pengumpulan data dilakukan dengan partisipasi multi pihak antara lain: Badan Informasi Geospasial, Pemerintah Kabupaten Siak, LPPM Universitas Riau, dan World Research Institute. Metode pengembangan peta spasial dilakukan dengan menggunakan aplikasi Avenza Maps berbasis android dan Arc Gis. Kegiatan dilakukan di Kecamatan Bunga Raya Kabupaten Siak. Kegiatan pengembangan dilakukan melalui tahapan persiapan (identifikasi kebutuhan dan pelatihan), pelaksanaan (pemetaan lapangan) dan evaluasi (pembuatan peta spasial desa dan verifikasi). Hasil pengembangan peta potensi desa berbasis spasial menunjukkan hasil yang baik. Pada tahapan persiapan menghasilkan teridentifikasinya komponen yang dibutuhkan, seperti: peta dasar, pengembangan SDM mahasiswa dengan melakukan pelatihan penggunaan aplikasi Avenza Maps. Pada tahapan pelaksanaan menghasilkan koordinat spasial potensi desa melalui survei lapangan secara partisipatif antara mahasiswa Universitas Riau dengan masyarakat/aparatur desa yang melibatkan pihak Kecamatan. Tahap evaluasi menghasilkan peta spasial yang telah terverifikasi oleh pihak Pemerintah Kabupaten Siak, terutama batas administratif desa. Hasil pemetaan spasial yang diperoleh dapat digunakan sebagai basis data dalam perencanaan pembangunan dan dapat digunakan sebagai baseline data spasial Kabupaten Siak.
\end{abstract}

Kata Kunci: Kabupaten Siak, Kecamatan Bunga Raya, peta spasial, potensi desa

\section{Development of Spatial Based Village Potential Map to Support Village Development Planning in the Flower District of Siak Regency}

\begin{abstract}
Village development planning requires information in the form of spatial data that is precise and accurate so that it can be used to analyze development needs in environmental, economic, and social aspects. It shows the limited spatial information related to village administration, village potential, and toponymy. The development of a spatial-based village potential map aims to present spatial information to be used in village development planning. The spatial map was developed through a participatory approach by involving Riau University students. Data collection was carried out with multi parties' participation, including the Geospatial Information Agency, Siak Regency Government, LPPM Riau University, and the World Research Institute. The method of developing spatial maps is done using the Avenza Maps application based on android and Arc Gis. The activity was carried out in Bunga Raya District, Siak Regency. Development activities are carried out through the stages of preparation (identification of needs and training), implementation (field mapping), and evaluation (making village spatial maps and verification). The results of developing a spatial-based village potential map showed promising results. The preparation stage resulted in identifying the components needed, such as base
\end{abstract}


maps, developing student human resources by conducting training on using the Avenza Maps application. The implementation stage produces spatial coordinates of the village potential through participatory field surveys between Riau University students and the District's community/village apparatus. The evaluation stage produces spatial maps that have been verified by the Siak Regency Government, especially the village administrative boundaries. Thus, spatial mapping results can be used as a database in development planning and can be used as a baseline for spatial data for Siak Regency.

Keywords: Siak Regency, Bunga Raya District, spatial map, village potential

\section{PENDAHULUAN}

Berdasar Undang-Undang Republik Indonesia Nomor 6 Tahun 2014 tentang Desa dan Undang-Undang Republik Indonesia Nomor 26 Tahun 2007 tentang Penataan Ruang, setiap desa wajib membuat perencanaan pembangunan. Dalam upaya pembangunan desa, memerlukan perencanaan yang matang serta data karakteristik desa yang tepat untuk membuat kebijakan. Data-data karakteristik desa ini diantaranya administrasi desa, potensi desa, dan toponimi. Data tersebut mempunyai peranan penting karena dapat dimanfaatkan untuk menganalisis aspek lingkungan, ekonomi, dan sosial yang dapat membantu pemerintah dalam membuat kebijakan.

Data batas administrasi, potensi desa, dan toponimi ini umumnya disajikan dalam format spasial yang diperoleh dengan cara pemetaan desa. Peta menjadi acuan tata ruang secara detail dalam melaksanakan pembangunan. Selain untuk memperoleh data tersebut, pemetaan desa bermanfaat untuk keperluan perencanaan, pembangunan, pengendalian wilayah, pengawasan serta mempercepat proses tata batas dan tata ruang kawasan desa. Pemetaan desa juga didukung dengan adanya Peraturan Presiden Republik Indonesia Nomor 09 Tahun 2016 tentang Percepatan Pelaksanaan Kebijakan Satu Peta dan Peraturan Kepala BIG Nomor 3 Tahun 2016 tentang Spesifikasi Teknis Penyajian Peta Desa.

Kecamatan Bunga Raya yang terletak di Kabupaten Siak merupakan daerah yang memiliki luas wilayah $151 \mathrm{~km}^{2}$. Kecamatan Bunga Raya terdiri dari 10 kampung/desa, yakni diantaranya: Desa Jaya Pura, Desa Bunga Raya, Desa Jati Baru, Desa Buantan Lestari, Desa Tuah Indrapura, Desa Kemuning Muda, Desa Langsat Permai, Desa Suak Merambai, Desa Dayang Suri, dan Desa Temusai (Bunga Raya, 2008). Masing-masing wilayah desa satu sama lain saling berbatasan dan hal ini masih ditemukannya wilayah yang saling tumpang tindih dalam hal batas desa. Batas desa yang belum jelas ini jelas akan menghambat di dalam perencanaan pembangunan desa karena terkait dengan tata batas kawasan. Selain tata batas yang menjadi permasalahan, masing-masing desa juga perlu melakukan pemetaan terkait potensi desa melalui aktivitas pemetaan desa.

Kegiatan inventarisasi dan pemetaan potensi desa sangat penting peranannya guna mendukung perencanaan pembangunan desa. Untuk mendukung swasembada desa melalui pembaruan data (updateting) yang dituangkan pada profil desa perlu diperbaharui dan dipetakan lokasi spasialnya serta dianalisis luasannya didapati dapat membantu perekonomian masyarakat dengan mengetahui potensi desa secara detail dan akurat (Handayani dan Cahyono, 2014). Hal yang sama juga dilakukan oleh (Nugroho et al., 2016) yang berlokasi di Desa Muara Sungsang, Kabupaten Banyuasin, Sumatera 
Selatan. Pengembangan peta yang dilakukan Nugroho dkk untuk melihat potensi desa di dalam pengelolaan sumber daya berbasis lahan, dimana data-data yang sudah dibuat telah menjadi acuan dasar dan masukkan untuk pembangunan serta bisa di pantau sesuai dengan arah pembangunan berkelanjutan melalui rencana pembangunan desa.

Sulitnya memperoleh data spasial yang akurat dan mumpuni, menyebabkan masalah dalam pemetaan spasial. Selain sulit untuk diperoleh karena wilayah studi yang besar, data yang tersedia umumnya bukan data terkini (outdate) sehingga pembuatan kebijakan menggunakan data tersebut menjadi tidak tepat. Oleh sebab itu perlu dilakukan pengembangan data spasial dalam rangka mendukung perencanaan pembangunan desa di Kecamatan Bunga Raya Kabupaten Siak. Keunggulan data spasial tersebut dapat memberikan informasi potensi desa terbaru yang lengkap serta akurat.

Kegiatan ini bertujuan untuk mengembangkan peta potensi desa berbasis spasial khususnya untuk mendukung perencanaan pembangunan desa di Kecamatan Bunga Raya Kabupaten Siak.

\section{METODOLOGI}

Peta spasial dikembangkan melalui pendekatan partisipatif dengan melibatkan mahasiswa Universitas Riau. Pengumpulan data dilakukan dengan partisipasi multi pihak antara lain: Badan Informasi Geospasial, Pemerintah Kabupaten Siak, LPPM Universitas Riau, dan World Research Institute (WRI). Metode pengembangan peta spasial dilakukan dengan menggunakan aplikasi Avenza Maps berbasis android dan Arc Gis. Kegiatan pengembangan dilakukan dengan tahap persiapan, pelaksanaan, dan evaluasi.

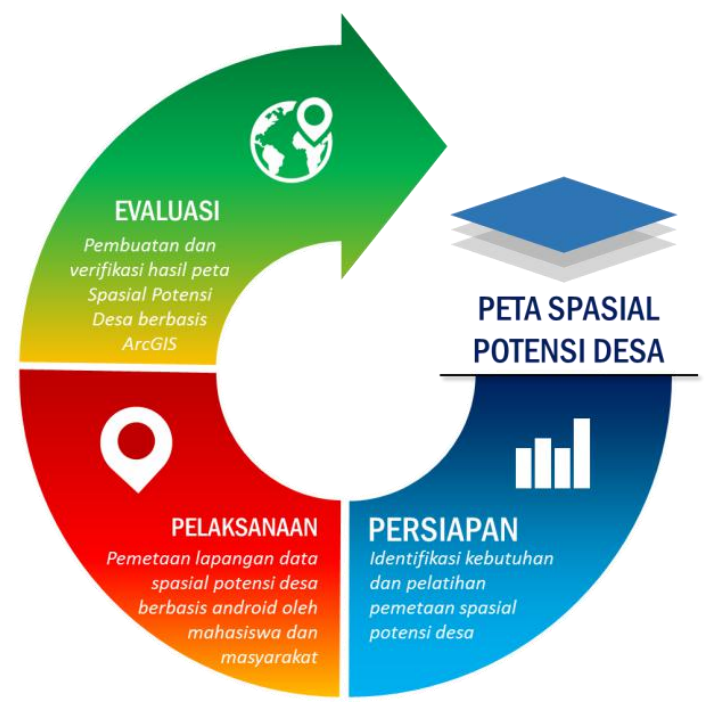

Gambar 1. Tahapan Pemetaan Potensi Desa Berbasis Spasial

Tahapan Pemetaan Potensi Desa Berbasis Spasial selengkapnya disajikan sebagai berikut: 
1. Tahapan Persiapan, meliputi: (1) kegiatan identifikasi kebutuhan data potensi desa yang ingin dipetakan oleh pemerintah desa, kecamatan dan kabupaten; (2) Melaksanakan pelatihan pemetaan spasial potensi desa melalui aplikasi Avenza Maps berbasis android kepada mahasiswa Universitas Riau.

2. Tahapan Pelaksanaan, meliputi: pemetaan lapangan pengambilan titik koordinat potensi desa oleh mahasiswa dan perwakilan masyarakat desa, dimana pada tahapan ini menghasilkan titik-titik koordinat. Pemetaan lapangan dilakukan dengan melibatkan mahasiswa Universitas Riau yang telah mengikuti pelatihan pemetaan desa.

3. Tahapan Evaluasi, meliputi: (1) analisis dan pembuatan peta spasial potensi desa berdasarkan hasil pemetaan lapangan; dan (2) verifikasi data hasil pemetaan peta spasial potensi desa. Analisis dan pembuatan peta spasial potensi desa dilakukan dengan menggunakan Aplikasi ArcGIS (Arc-Geographic Information System) sedangkan verifikasi hasil pemetaan dilakukan kolaboratif para pihak.

\section{HASIL DAN PEMBAHASAN}

Kegiatan pemetaan spasial potensi desa dilakukan untuk mengembangkan peta potensi desa berbasis spasial. Sehingga memudahkan para pihak untuk mengetahui secara detail sebaran potensi desa pada setiap desa di Kecamatan Bunga Raya, Kabupaten Siak. Kegiatan pengembangan peta potensi desa berbasis spasial dilakukan melalui 3 (tiga) tahapan, yakni; (1) persiapan; (2) pelaksanaan, dan; (3) evaluasi.

\section{Persiapan Pemetaan Potensi Desa}

Pada tahapan persiapan yang dilakukan pertama sekali adalah mengidentifikasi kebutuhan, dimana terdapat data, peralatan, dan bahan yang perlu dipersiapkan. Adapun kebutuhan data yang diperlukan meliputi; (a) profil desa; (b) indikatif batas kecamatan; (c) indikatif batas desa; (d) toponimi; (e) tutupan lahan; (f) permukiman; (g) peta dasar, dan; (h) batas desa. Sementara peralatan dan bahan yang diperlukan meliputi; (a) GPS; (b) Avenza Maps basis android; (c) tanda batas sementara; (d) peta kerja, dan; (e) berita acara persetujuan. Setelah selesai mengumpulkan kebutuhan pemetaan maka dilakukan kegiatan pelatihan pemetaan spasial potensi desa berbasis android kepada mahasiswa Universitas Riau. Pelatihan diberikan oleh Pusat Pengembangan Infrastruktur Informasi Geospasial (PPIIG) UNRI dan WRI Indonesia kepada mahasiswa sebanyak 10 orang pada tanggal 28 Juni 2019 di Gedung LPPM UNRI.

Selanjutnya sosialisasi dan pelatihan pemetaan dasar yang kedua diberikan oleh PPIIG UNRI dan WRI Indonesia kepada masyarakat (perwakilan) desa di Aula Kecamatan Bunga Raya pada tanggal 31 Juli 2019, bertempat di Aula Kantor Camat Bunga Raya. Sosialisasi dan pelatihan yang telah dilakukan menekankan aktivitas partisipatif di dalam pelaksanaanya, dimana masyarakat lokal mempunyai kapasitas dan pengetahuan yang mendalam mengenai lingkungan tempat tinggalnya (Thomas-Slayter, 1995). 

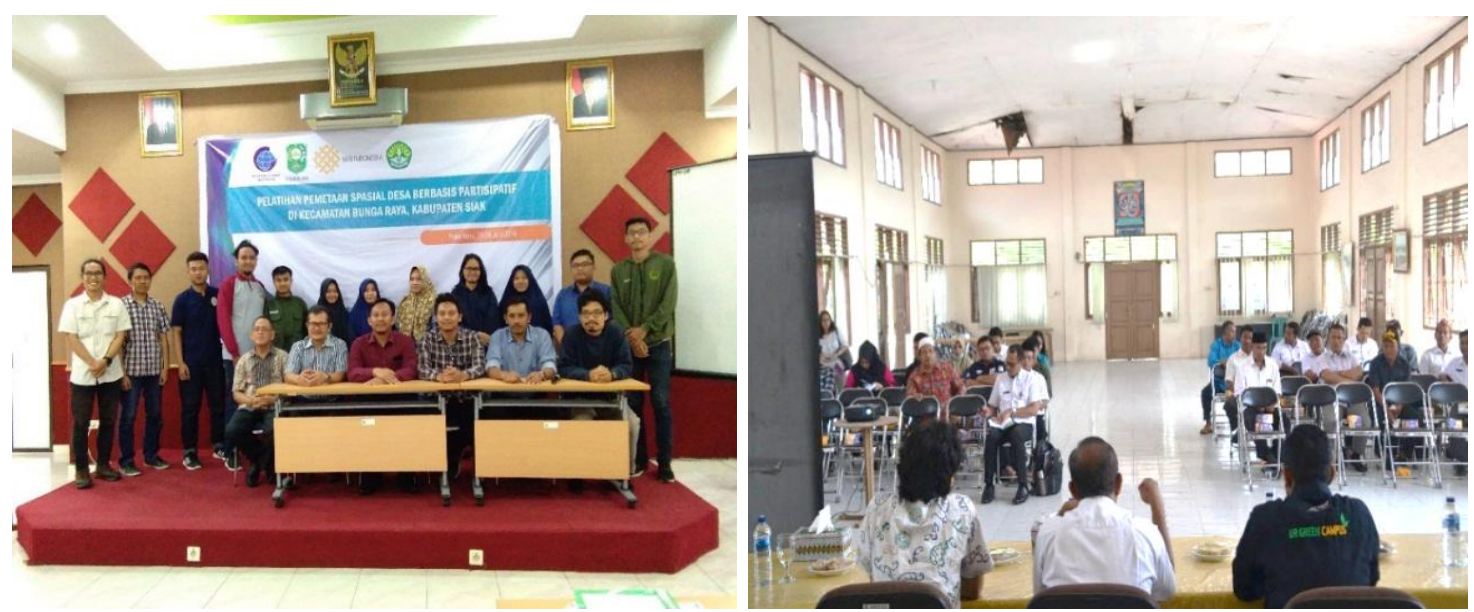

Gambar 2. Sosialisasi dan Pelatihan Kepada Mahasiswa Unri dan Masyarakat Desa

\section{Pelaksanaan Pemetaan Potensi Desa}

Setelah dibekali pembekalan pelatihan pemetaan, mahasiswa Universitas Riau dan masyarakat desa selanjutnya melaksanakan pemetaan. Pemetaan dilaksanakan dengan menggunakan pendekatan pemetaan secara partisipatif. Pemetaan partispatif sendiri dapat didefinisikan sebagai metode pemetaan yang melibatkan masyarakat dan menempatkan masyarakat sebagai pelaku pemetaan di wilayahnya (Hidayat et al., 2005). Lebih lanjut Hidayat et al., (2005) menjelaskan pemetaan partisipatif sebagai salah satu alternatif teknik perolehan data spasial antara lain di bidang pengelolaan sumber daya alam, perencanaan aktivitas pertanian, implementasi lokasi penempatan sarana pendidikan dan kesehatan, penegasan batas wilayah, dan pengurangan risiko bencana. Contoh-contoh keberhasilan penerapan pemetaan partisipatif di Indonesia untuk pemetaan batas wilayah maupun sumber daya pada tingkat desa antara lain oleh (Budisusanto et al., 2014) dan (Mardiah, 2015).
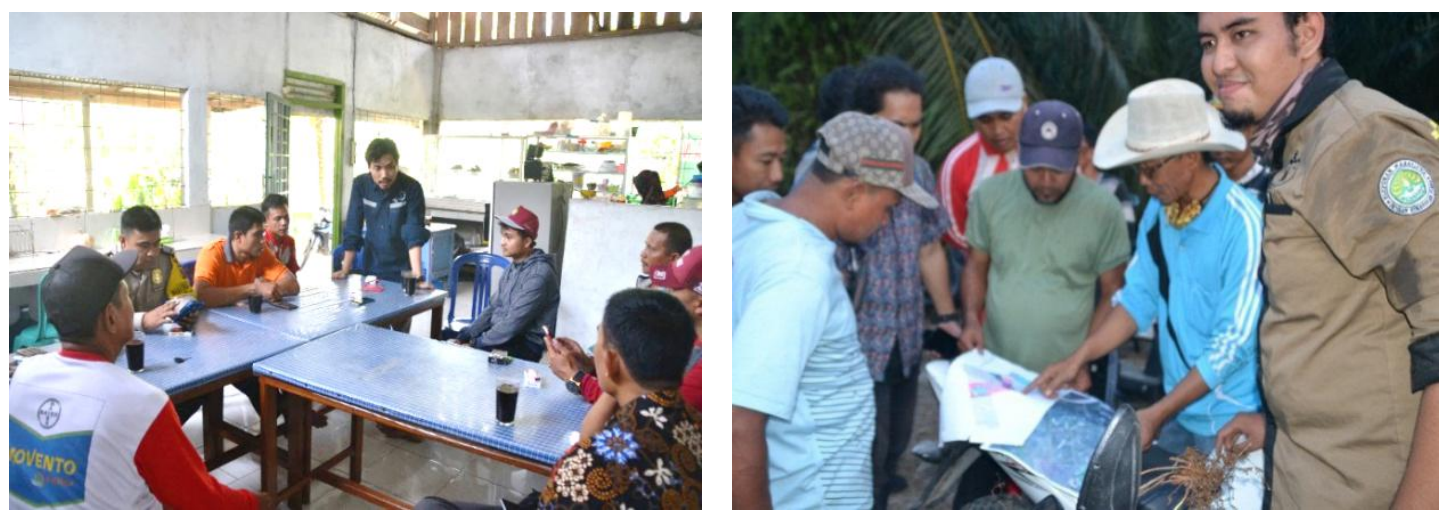

Gambar 3. Pembagian Kelompok Kerja dan Pengambilan Data Bersama di Lapangan

Pendampingan, mahasiswa dan masyarakat diarahkan ke lapangan untuk mengambil data titik koordinat pada masing-masing desa. Pengambilan titik koordinat 
dilakukan menggunakan Avenza Maps. Data yang diambil meliputi; (a) data indikatif batas kecamatan dan desa; (2) data spasial toponimi desa, seperti: fasilitas kesehatan, fasilitas pendidikan, kantor pemerintahan, dan fasilitas umum; serta (3) data koordinat permukiman. Sebelum diarahkan ke lapangan terlebih dahulu dibentuk tim dengan maksud membagi pekerjaan agar pelaksanaan berjalan efektif dan efisien (Gambar 3).

\section{Evaluasi Hasil Pemetaan Potensi Desa}

Pengambilan data titik koordinat yang sudah selesai dilakukan dengan menggunakan Avenza Maps, yang di dalamnya memuat informasi spasial berupa titik koordinat akan dipindahkan ke komputer. Hasil dari input data ini dapat dibuka dan dianalisis dalam perangkat lunak melalui aplikasi ArcGIS. ArcGIS dapat digunakan untuk pengolahan data atribut maupun spasial secara umum seperti melakukan overlay layer, manipulasi data vektor dan raster, menghitung luasan suatu wilayah, memberikan informasi tambahan (titik, garis, dan polygon) ataupun menyusun layout peta. Wibawa dan Zulfikar (2017) menyatakan ArcGIS sangat layak untuk dijadikan alternatif perangkat lunak pemetaan dalam berbagai keperluan seperti pemetaan untuk tata ruang ataupun penyusunan peta-peta tematik dalam berbagai penelitian.

Sebelum menyelesaikan draft peta, dilakukan verifikasi dan validasi peta untuk memastikan kualitasnya. Proses verifikasi dan validasi dilakukan secara bersama pemerintah desa, hal ini perlu sebab apabila data peta yang diperoleh atau dikumpulkan masih belum lengkap, maka tim pemetaan desa akan melengkapinya. Marjuki (2018) menyatakan verifikasi dan validasi data dilakukan untuk memastikan tidak adanya kesalahpahaman antara informasi yang digambarkan dalam kegiatan pemetaan partisipatif oleh nara sumber, dengan peneliti yang menterjemahkan hasil pemetaan partisipatif dalam bentuk data geospasial digital.
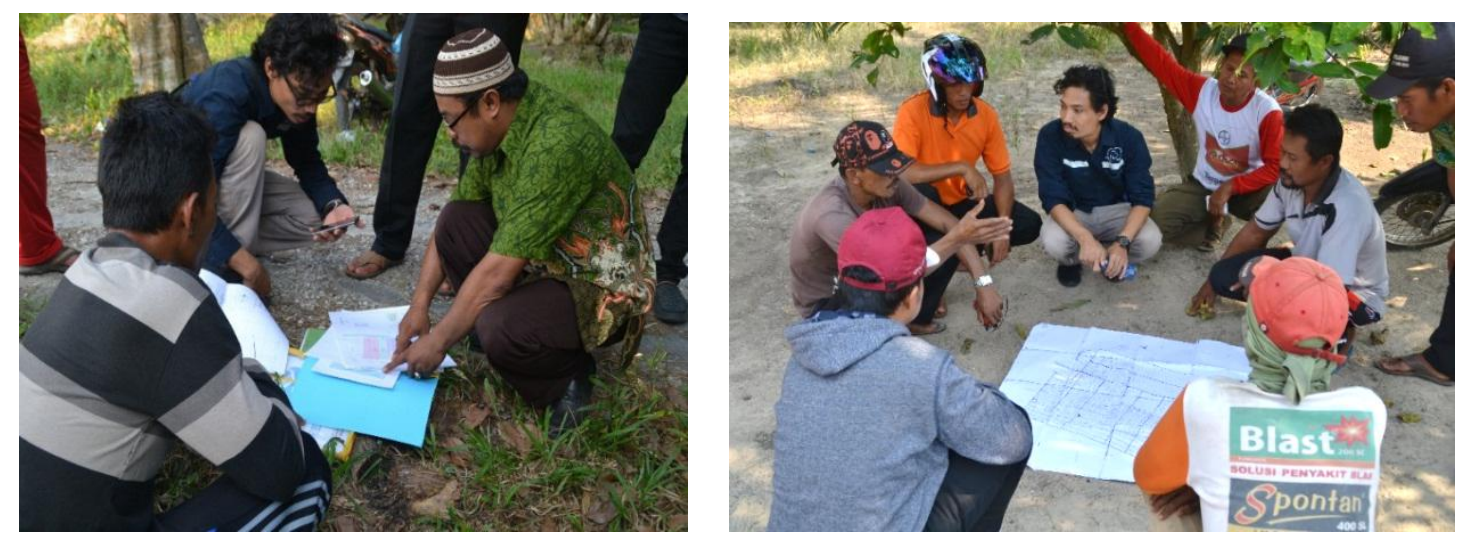

Gambar 4. Proses Verifikasi dan Validasi Peta

Proses verifikasi dan validasi desa sudah dirasa lengkap maka langkah terakhir adalah proses pembuatan final peta desa. Hasil informasi yang diperoleh atau dikumpulkan akan diintegerasikan dalam sebuah peta. Peta ini akan dipersiapkan untuk dipresentasikan kepada masyarakat. 


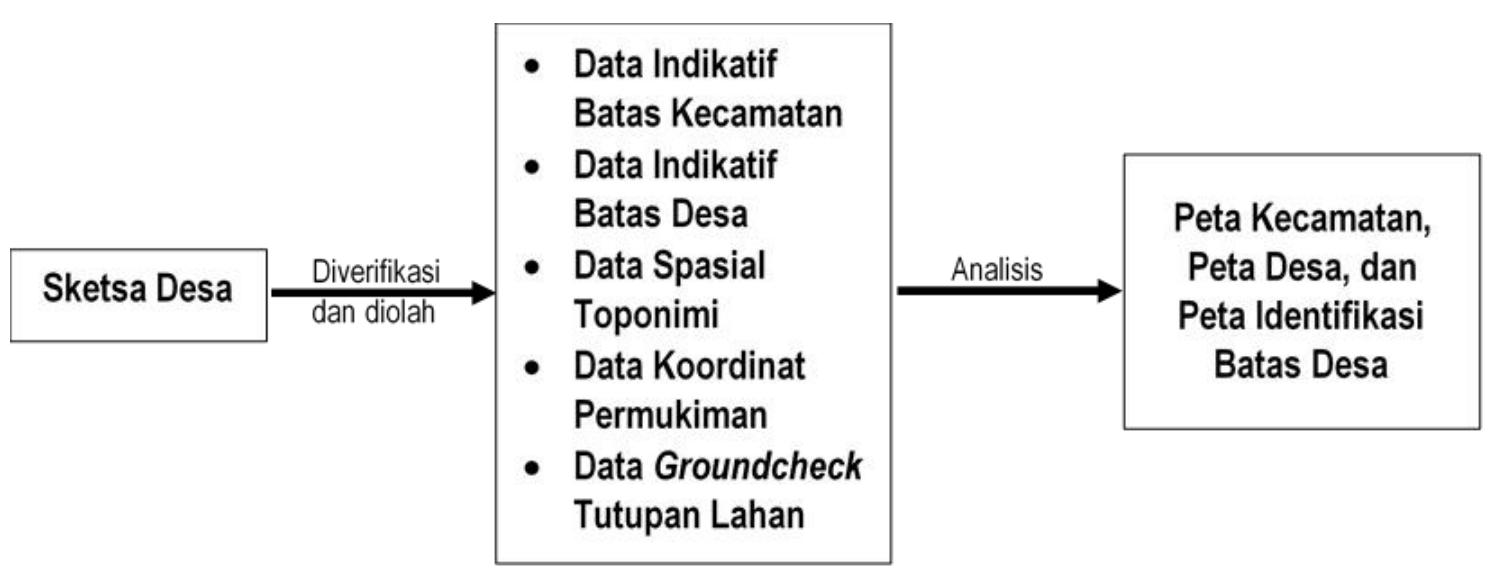

Gambar 5. Diagram Alir Finalisasi Peta Desa

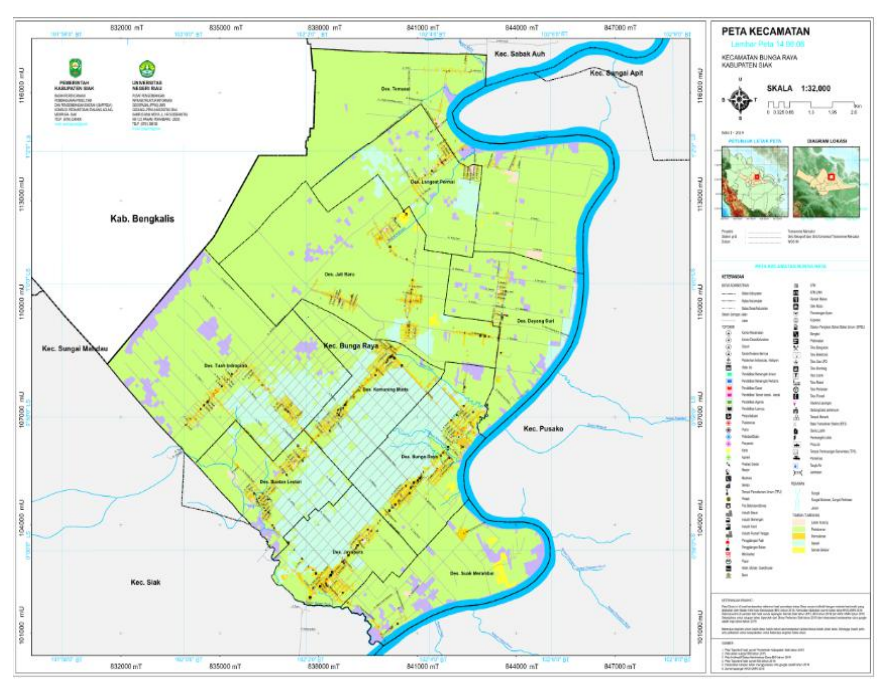

Gambar 6. Peta Spasial Kecamatan Bunga Raya

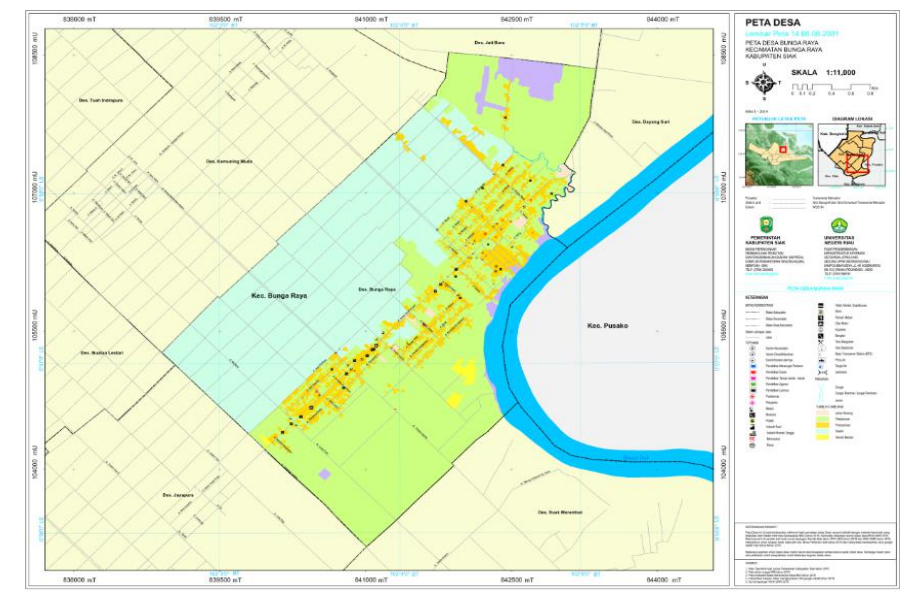

Gambar 7. Peta Spasial Desa Bunga Raya 


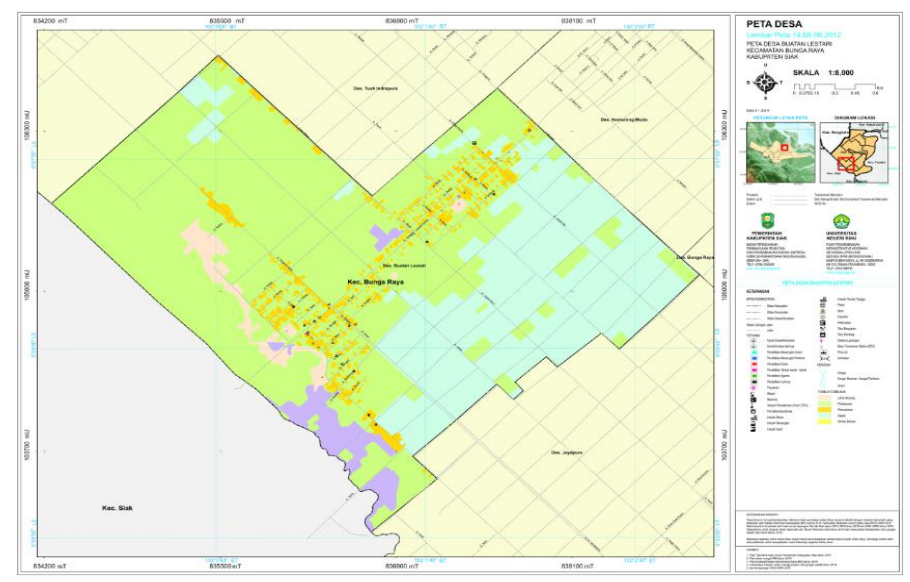

Gambar 8. Peta Spasial Desa Buantan Lestari

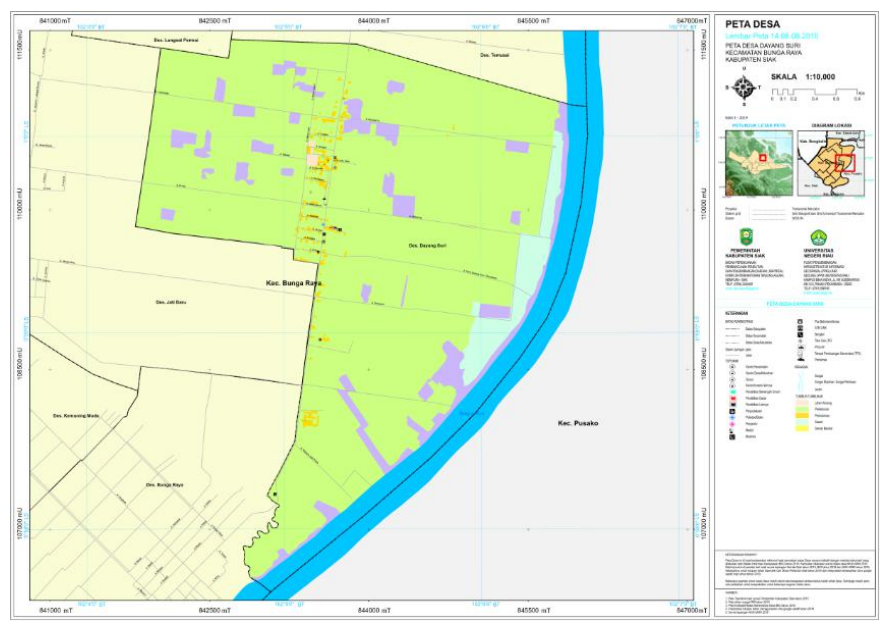

Gambar 9. Peta Spasial Desa Dayang Suri

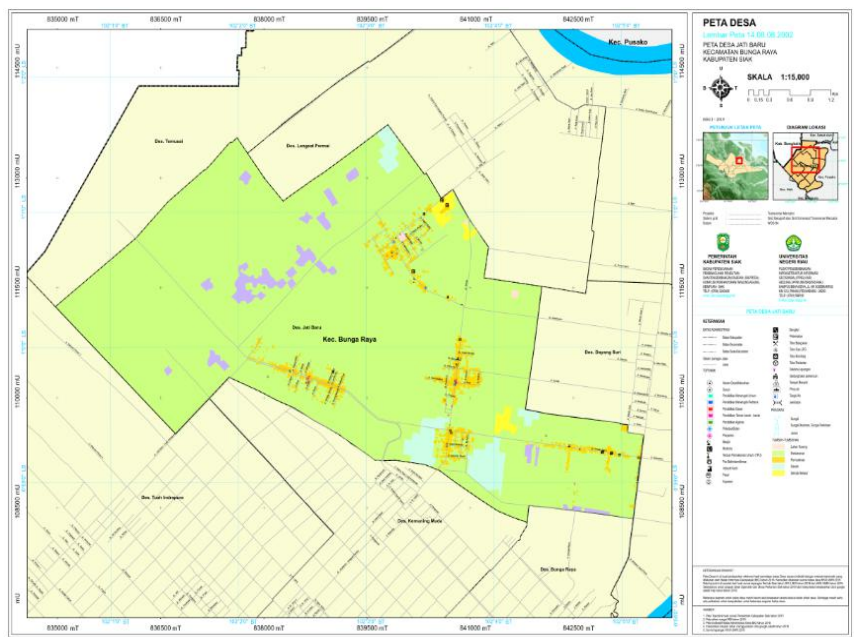

Gambar 10. Peta Spasial Desa Jati Baru 


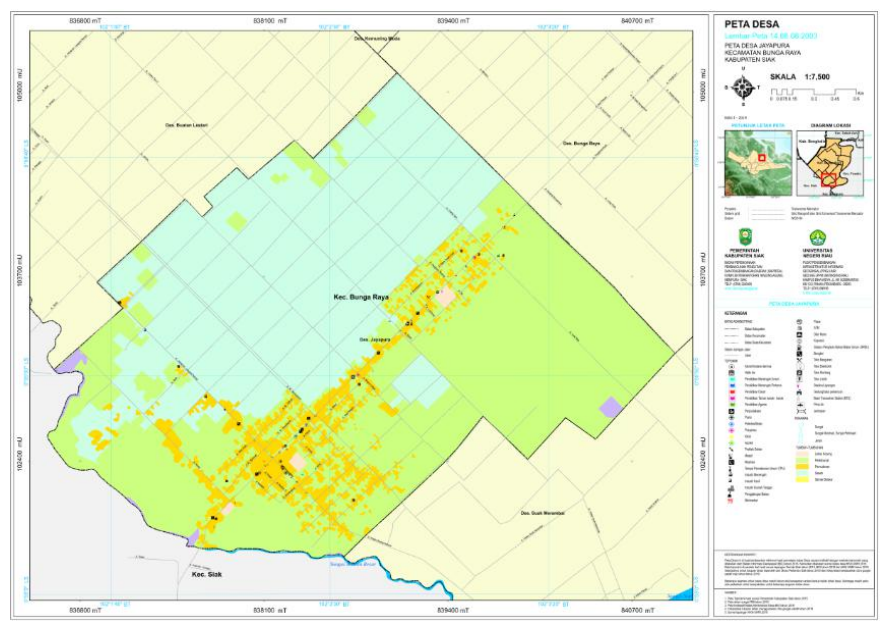

Gambar 11. Peta Spasial Desa Jayapura

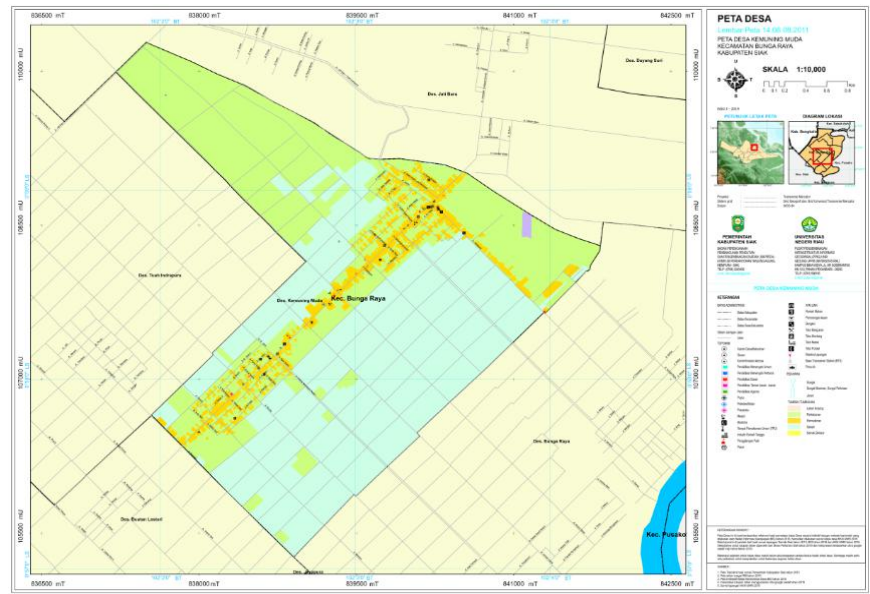

Gambar 12. Peta Spasial Desa Kemuning Muda

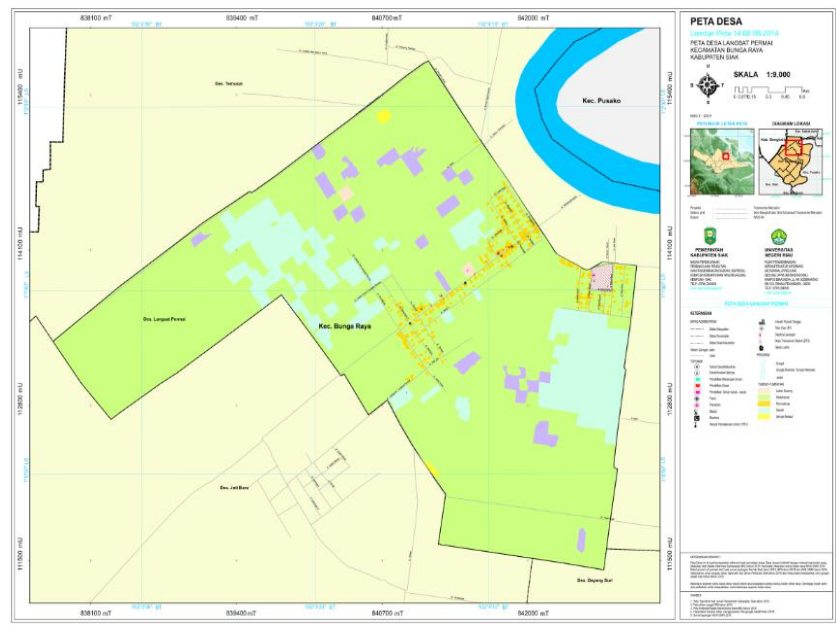

Gambar 13. Peta Spasial Desa Langsat Permai 


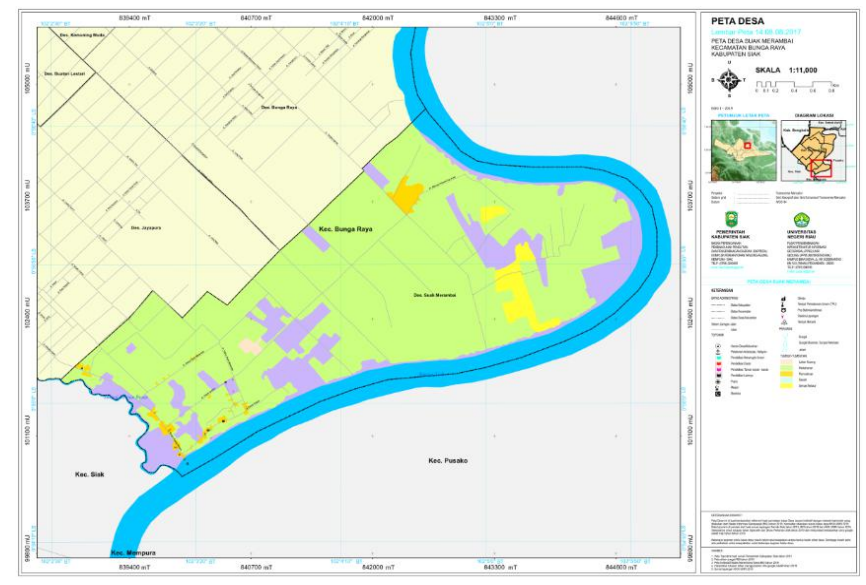

Gambar 14. Peta Spasial Desa Suak Merambai

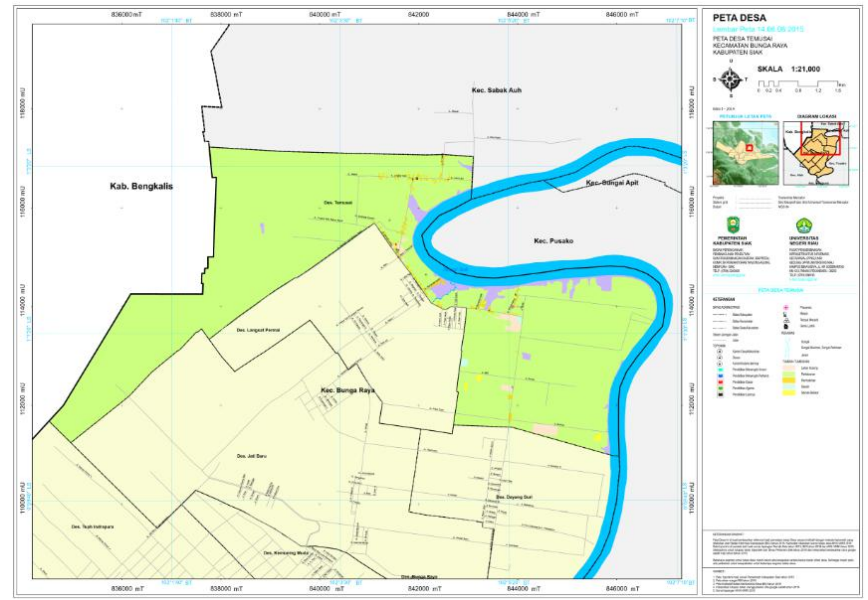

Gambar 15. Peta Spasial Desa Temusai

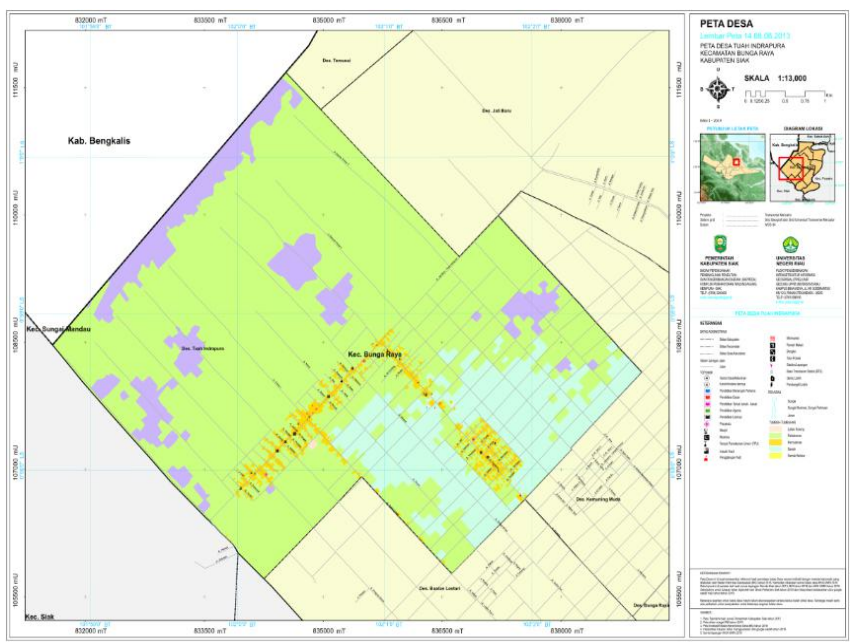

Gambar 16. Peta Spasial Desa Tuah Indrapura 


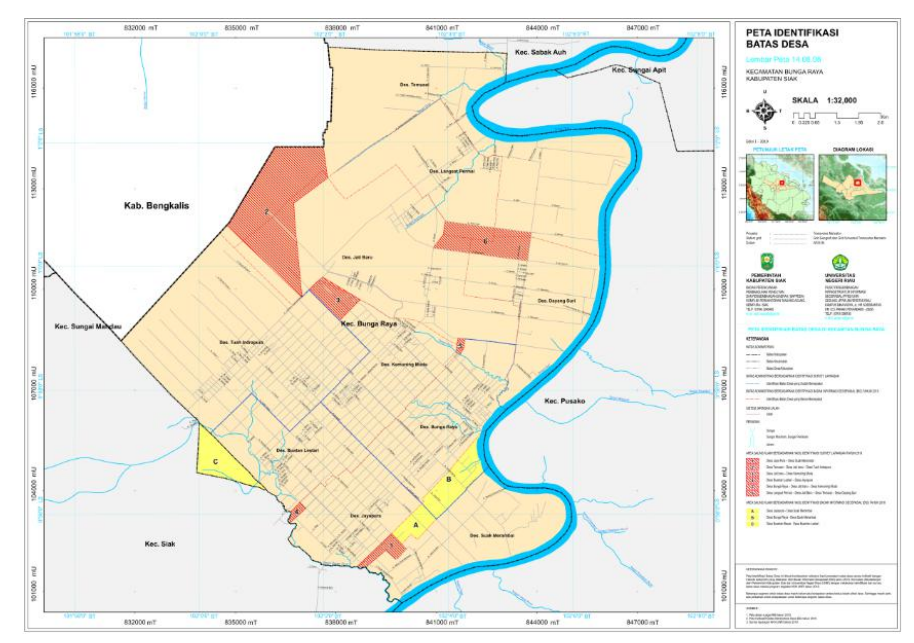

Gambar 17. Peta Spasial Identifikasi Batas Desa

Setelah peta final desa seluruh Kecamatan Bunga Raya rampung dan dipresentasikan kepada perwakilan masyarakat ternyata masih memiliki kelemahan, yakni pada batas wilayah administrasi beberapa desa. Kelemahan tersebut ada pada permasalahan tata batas lahan, diantaranya terkait batas lahan/batas beberapa desa di Kecamatan Bunga Raya yang belum memiliki kesepakatan untuk tata batas seperti Desa Jati Baru, Desa Temusai, Desa Langsat Permai, Desa Jayapura, dan Desa Tuah Bestari. Tindakan lanjut yang dilakukan selanjutnya adalah melakukan koordinasi dengan pemerintah daerah Kabupeten Siak. Dari hasil koordinasi tersebut terkait penyelesaian tata batas lahan atau administrasi dapat dilaksanakan oleh Pemerintahan Kabupaten Siak karena kewenangan besar untuk aturan tata batas pemerintahan berada pada kewenangan pemerintah Kabupaten Siak.

Maka dari itu peta pemetaan partisiaptif desa yang dihasilkan dari kegiatan ini khususnya batas desa pada kegiatan ini masih indikatif yang belum bisa dijadikan acuan resmi. Pada Permendagri No. 45 Tahun 2016 tentang Pedoman Penetapan dan Penegasan Batas Desa, Proses Penetapan, dan Penegasan Batas Desa perlu dilaksanakan oleh Tim PPBDes Kabupaten/Kota dengan alat ukur yang lebih detail agar menjadi definitif dan disahkan melalui Peraturan Bupati (Perbup). Namun demikian, pemetaan batas desa indikatif yang dilakukan pada kegiatan ini diharapkan dapat digunakan sebagai baseline data maupun acuan dasar untuk mempermudah Tim PPBDes dalam mengidentifikasi peta batas desa yang telah disepakati, sehingga dapat dibuat berita acara kesepakatan antar desa di dalam Kecamatan Bunga Raya untuk kemudian dilakukan proses selanjutnya.

Berbagai informasi spasial dapat diterjemahkan ke dalam obyek spasial (peta). Peta yang sudah jadi dikatakan sebagai peta final di dalam pelaksanaan kegiatan pemetaan partisipatif dimana di dalamnya memuat informasi yang komprehensif. Kegiatan ini sangat dirasakan manfaatnya oleh masyarakat desa dan pemerintahan desa, yakni dengan adanya pemetaan secara partisipatif yang sudah dilaksanakan berdampak terhadap meningkatnya kesadaran dan semangat masyarakat dalam hal pengembangan potensi yang ada di wilayah desa masing-masing sehingga dapat dimaksimalkan di dalam perencanaan kerja pembangunan desa ke depannya, selain itu juga masyarakat 
dapat mengenali batas antar desa yang mana sebelumnya sebagian besar masyarakat tidak mengetahui batas pasti wilayah desa masing-masing atau dapat dikatakan memiliki kekeliruan dalam batas. Selain masyarakat, hasil pemetaan spasial juga dapat digunakan baseline data spasial Kabupaten Siak. Kegiatan ini pun sangat didukung oleh pihak Pemerintah Daerah Siak sehingga pelaksanaan program ini berjalan dengan baik.

\section{KESIMPULAN DAN SARAN}

Kegiatan pengembangan peta potensi desa berbasis spasial telah menghasilkan informasi spasial berupa obyek spasial (peta) dan data spasial potensi desa di Kecamatan Bunga Raya Kabupaten Siak. Hasil pemetaan spasial dapat digunakan sebagai basis data dalam perencanaan pembangunan dan dapat digunakan sebagai baseline data spasial Kabupaten Siak. Kegiatan pengembangan peta dikembangkan melalui pendekatan partisipatif dengan melibatkan mahasiswa dan masyarakat desa sehingga hal tersebut sangat dirasakan manfaatnya oleh masyarakat desa dan pemerintahan desa, yakni dengan adanya pemetaan secara partisipatif berdampak terhadap meningkatnya kesadaran dan semangat masyarakat dalam hal pengembangan potensi yang ada di wilayah desa masing-masing sehingga dapat dimaksimalkan di dalam perencanaan kerja pembangunan desa ke depannya, selain itu juga masyarakat dapat mengenali batas antar desa yang mana sebelumnya sebagian besar masyarakat tidak mengetahui batas pasti wilayah desa masing-masing atau dapat dikatakan memiliki kekeliruan dalam batas.

Peta yang dihasilkan dari kegiatan ini khususnya batas desa masih indikatif yang belum bisa dijadikan acuan resmi. Atas dasar itu perlu dilakukan tindak lanjut oleh Pemerintah Kabupaten Siak untuk menyelesaikan tata batas desa yang belum disepakati dengan mengikuti aturan Permendagri No. 45 Tahun 2016 tentang Pedoman Penetapan dan Penegasan Batas Desa, Proses Penetapan, dan Penegasan Batas Desa perlu dilaksanakan oleh Tim PPBDes Kabupaten/Kota dengan alat ukur yang lebih detail agar menjadi definitif dan disahkan melalui Peraturan Bupati (Perbup).

\section{UCAPAN TERIMA KASIH}

Ucapan terima kasih disampaikan kepada para pihak yang mendukung kegiatan pemetaan potensi desa berbasis spasial di Kecamatan Bunga Raya Kabupaten Siak meliputi: Pemerintah Kabupaten Siak, Jaringan Informasi Geospasial Daerah Siak, Pemerintah Desa dan Kecamatan Bunga Raya, WRI Indonesia, serta Lembaga Penelitian dan Pengabdian kepada Masyarakat (LPPM) Universitas Riau melalui dukungan program pengabdian masyarakat serta Mahasiswa Kukerta Universitas Riau di Kecamatan Bunga Raya. 


\section{DAFTAR PUSTAKA}

Budisusanto, Y., Khomsin, K., Purwanti, R., Nurry, A. and Widiastuty, R., 2014. Pemetaan Partisipatif Batas Kelurahan Di Kecamatan Sukolilo Kota Surabaya. Jurnal Geoid,. Vol. 10 No. 1: 87-92

Efrizal., Rusnam dan F.L. Syaiful. 2018. Diseminasi teknologi pembuatan pakan buatan alternatif dengan campuran limbah kangkung air, Ipomoea aquatica Forks untuk pembudidaya ikan di Sumatera Barat. Jurnal Hilirisasi IPTEKS. 1(3):110.

Handayani, H dan Cahyono, A.B., 2014. Pemetaan partisipatif potensi desa (Studi kasus: Desa Selopatak Kecamatan Trawas Kabupaten Mojokerto. Jurnal Geoid. 10 (1): $99-103$

Hidayat, R., Adhi, W., \& Bachriadi D. 2005. Seri Panduan Pemetaan Partisipatif. Garis Pergerakan, Bandung.

Mardiah. 2015. Pemetaan potensi sumber daya alam guna meningkatkan kesejahteraan masyarakat di Kecamatan Tukak Sadai Kabupaten Bangka Selatan. Jurnal Pengabdian kepada masyarakat Universitas Bangka Belitung. Vol. 2 No. 1: 40-50.

Marjuki, B. 2018. Penerapan Teknik Pemetaan Partisipatif untuk Mendukung Penyusunan Basis Data Spasial Penggunaan Lahan dan Sumberdaya Desa. Proseding Seminar Nasional Geomatika 2018: Penggunaan dan Pengembangan Produk Informasi Geospasial Mendukung Daya Saing Nasional, Jakarta.

Nugroho, D., Budianto, A., Yunus, M., Partisipatif, P., Desa, P., Desa, T., Sungsang, M. and Penyusun, T., 2016. Participatory Mapping and RaTA in Muara Sungsang Village. GIZ BIOCLIME, Jakarta.

Thomas-Slayter, B. 1995. A Brief History of Participatory Methodologies. Intermediate Technology Publications, London.

Syaiful F.L, Uyung Gatot S. Dinata dan Ferido. 2018. Pemberdayaan masyarakat Nagari Sontang Kabupaten Pasaman melalui inovasi budidaya sapi potong dan inovasi pakan alternatif yang ramah lingkungan. Buletin Ilmiah Nagari Membangun. Vol. 1 No. 3, September 2018.

Syaiful F.L, Uyung Gatot S. Dinata dan Yondra Hidayattullah. 2018. Pemberdayaan masyarakat melalui pemanfaatan limbah sekam padi sebagai bahan bakar kompor sekam yang ramah lingkungan di Kinali, Pasaman Barat. Buletin Ilmiah Nagari Membangun. Vol. 1 No. 3, September 2018. 
Syaiful F.L. 2018. Diseminasi teknologi deteksi kebuntingan dini "DEEA GestDect" terhadap sapi potong di Kinali Kabupaten Pasaman Barat. Jurnal Hilisasi IPTEKS. 1(3): 17-25

Wibawa, C.J dan Zulfikar, R. 2017. Analisis dan pemetaan potensi daerah berbasis gis menggunakan model rasio pertumbuhan (MRP). Jurnal Teknik Informatika dan Sistem Informasi. Vol. 3 No. 3: 524-538. 